\title{
ANÁLISE DAS LICENCIATURAS EM CIÊNCIAS BIOLÓGICAS OFERTADAS PELA UNIVERSIDADE ESTADUAL PAULISTA (UNESP)
}

\author{
Patrícia Féboli ${ }^{1}$, Andréia Nunes Militão ${ }^{2}$ \\ ${ }^{1}$ Mestranda em Educação pelo Programa de Pós-Graduação em Educação da Universidade Estadual de Mato Grosso \\ do Sul - UEMS. E-mail: patriciafeboli@@hotmail.com. Financiamento: CAPES \\ ${ }^{2}$ Doutora em Educação pela Universidade Estadual Paulista - UNESP. Professora dos cursos de Licenciatura em \\ Pedagogia e Letras/Espanhol e do Programa de Pós-Graduação em Educação da Universidade Estadual de Mato \\ Grosso do Sul - UEMS.
}

\section{RESUMO}

Este trabalho integra a pesquisa de mestrado intitulada "A dimensão pedagógica nas licenciaturas em Ciências Biológicas: uma análise das universidades públicas paulistas". Encontra-se em desenvolvimento junto ao Programa de Pós-Graduação em Educação/ UEMS-Paranaíba. O delineamento do trabalho parte da indagação: A UNESP possui projeto unitário de formação de professores de Ciências Biológicas? Tem por objetivo analisar conteúdos de caráter pedagógico nos Projetos Pedagógicos dos Cursos de Ciências Biológicas oferecida nos campus da Universidade. Com abordagem qualitativa e delineamento descritivoexplicativo, elege como procedimentos metodológicos: pesquisa bibliográfica e pesquisa documental. A análise dos dados permite concluir que há variação curricular entre campus, compreendendo: diferenças de horas para integralização curricular, campus de Bauru (3270h), campus de Rio Claro (3930h); variação no

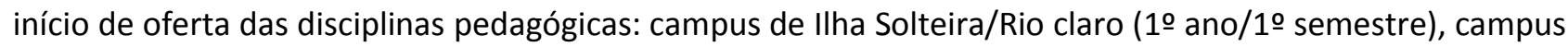
Bauru/Jaboticabal ( 20 ano/ 20 semestre).

Palavras-chave: Formação Inicial de Professores. Licenciatura em Ciências Biológicas. Variação Curricular. Dimensão Pedagógica. Projeto Pedagógico de Curso.

\section{ANALYSIS OF LICENSES IN BIOLOGICAL SCIENCES OFFERED BY UNIVERSIDADE ESTADUAL PAULISTA (UNESP)}

\section{ABSTRACT}

This work integrates the master's research entitled "The pedagogical dimension in biological sciences degrees: An analysis of the public universities of São Paulo." It is in development next to the graduate program in Education/UEMS-Paranaíba. The outline of the work part of the quest: does UNESP have a unitary project of formation of biological sciences teachers? It aims to analyze pedagogical content in the pedagogical projects of the biological sciences courses offered on the university campus. With qualitative approach and descriptive-explanatory outline, elects as methodological procedures: Bibliographical research and documentary research. Data analysis allows you to conclude that there is curricular variation between campus, comprising: differences of hours for curricular Integralization, Bauru Campus (3270h), Rio Claro Campus (3930h); Variation in the beginning of offer of pedagogical disciplines: Single Island Campus/Rio Claro (1st year/1st semester), Campus Bauru/Jaboticabal (2nd Year/2nd semester).

Keywords: Initial training of Teachers. Degree in biological sciences. Curricular variation. Pedagogical dimension. Pedagogical project of course.

\section{INTRODUÇÃO}

As discussões relacionadas às disciplinas responsáveis pela formação para a docência em cursos de licenciatura se direcionaram mais para o "[...] loteamento de horas na grade curricular [...]" (DIAS-DA-SILVA, 2005, p. 388) do que propriamente para os saberes necessários à formação para a docência e a importância deles 
para a formação do professor. Gatti e Nunes (2009) ressaltam que as disciplinas de formação específica e as de formação pedagógica não possuem articulação, reforçando os equívocos curriculares da formação inicial.

Prevalecem em meio às licenciaturas, discussões relacionadas às disciplinas responsáveis pela formação para a docência e disciplinas por área do conhecimento, aspecto que confirma a disputa de concepções sobre o campo da formação de professores, já que desde as origens das licenciaturas no início do século $X X$, a formação inicial nos cursos de licenciatura tornou-se uma espécie de combinado de disciplinas específicas e pedagógicas.

Desta forma, o desprestígio da dimensão pedagógica passa por questões que envolvem: quantidade de disciplinas/horas destinadas para cada um desses eixos, o lugar na estrutura curricular/série/ano/semestre a serem ofertadas as disciplinas de caráter pedagógico, qual dia da semana será ministrada, qual docente irá ministrá-la (efetivo, contratado), dentre outras particularidades.

Ao analisar a estrutura curricular dos primeiros cursos superiores no Brasil, nota-se a conexão dos cursos de formação de bacharéis no modelo $3+1$ (onde bacharéis tinham a possibilidade de continuar um ano na universidade, configurando uma espécie de complementação, para que pudessem obter diploma de licenciatura), e a atual Licenciatura.

Para Moreira (2012), as licenciaturas saíram do modelo $3+1$, porém este modelo continua consagrado nas licenciaturas. Conquanto possamos constatar mudanças curriculares nos cursos de Licenciatura, permanece $o$ tratamento diferenciado dos conteúdos pedagógicos que são abordados independentemente das disciplinas específicas de cada curso, não havendo vínculo/articulação entre elas.

Porém, mudanças vêm sendo colocadas em prática e impactando as universidades por meio de Leis e Resoluções implementadas. A Resolução $\mathrm{CNE} / \mathrm{CP} \mathrm{n}^{\circ} 1$ de 18 de fevereiro de 2002 estabeleceu as Diretrizes Curriculares Nacionais para a Formação de Professores da Educação Básica, em nível superior, curso de licenciatura, de graduação plena, constituindo um conjunto de princípios, fundamentos e procedimentos a serem observados na organização institucional e curricular de cada estabelecimento de ensino e aplicam-se a todas as etapas e modalidades da educação básica; Já, a Resolução CNE/CP $\mathrm{n}^{\circ} 2$ de 19 de fevereiro de 2002 institui a carga horária dos cursos de Formação de Professores da Educação Básica, em nível superior, em curso de licenciatura, de graduação plena.

Além das Resoluções citadas, tem-se em específico as Diretrizes Curriculares Nacionais para os Cursos de Ciências Biológicas, por meio da Resolução CNE/CES no 7, de 11 de março de 2002, segundo a qual a modalidade Licenciatura deverá contemplar, além dos conteúdos próprios das Ciências Biológicas, conteúdos nas áreas de Química, Física e da Saúde, com o objetivo de atender o ensino fundamental e médio, e a formação pedagógica, além de suas especificidades, devendo contemplar uma visão geral da educação e dos processos formativos dos educandos.

Com a incessante busca pelo aperfeiçoamento na formação inicial de professores, após as reestruturações realizadas pelas universidades, baseadas nas Diretrizes Curriculares de 2002, outras Resoluções foram aprovada no país - a Deliberação CEE no111/2012, que implanta as Diretrizes Curriculares Complementares para a Formação de Docentes para a Educação Básica nos Cursos de Graduação de Pedagogia, Normal Superior e Licenciaturas, oferecidos pelos estabelecimentos de ensino superior vinculados ao sistema estadual paulista; Deliberação CEE № 126/2014, que altera dispositivos da Deliberação 111/2012; a Resolução CNE/CP n. 2, de $1^{\circ}$ de julho de 2015, determinando mudanças nas diretrizes curriculares para a formação inicial em nível superior (cursos de licenciatura, cursos de formação pedagógica para graduados e cursos de segunda licenciatura) e para a formação continuada, como o aumento na carga horária desses cursos de 2.800 horas para 3.200 horas de efetivo trabalho acadêmico, em cursos com duração de, no mínimo, 8 (oito) semestres ou 4 (quatro) anos, compreendendo pelo menos 2.200 (duas mil e duzentas) horas dedicadas para os conteúdos curriculares de natureza científico cultural, 400 (quatrocentas) horas de prática como componente curricular, 400 (quatrocentas) horas de estágio curricular supervisionado, 200 (duzentas) horas para outras formas de atividades complementares; e a Deliberação CEE n. 154/2017, que dispõe sobre alteração da Deliberação CEE 111/2012. 
Sustentado por Mizukami (1996), é no curso de licenciatura que o futuro professor adquire conhecimentos que sustentam suas referências necessárias para exercer da profissão docente. Porém, é de grande valia enfatizar que a formação inicial sozinha não é suficiente para formar o professor, já que é necessária à construção de bases sólidas para o ensinoaprendizagem e os currículos dos cursos iniciais não proporcionam o conhecimento correspondente. Desta forma, o presente trabalho tem como objetivo analisar, a partir dos normativos legais, os cursos de Licenciatura em Ciências Biológicas. Almeja-se, desta maneira, discutir e analisar propostas de formação de professores de Ciências Biológicas localizados no estado de São Paulo, em específico, a formação oferecida pela Universidade Estadual Paulista "Júlio de Mesquita Filho" - UNESP. Portanto, centra-se, especialmente, na análise da operacionalização e funcionamento dos cursos, bem como na análise da estrutura curricular dos mesmos, dentre todos os campus que apresentam o curso em questão, procurando responder à questão: Qual é o lugar da dimensão pedagógica nas licenciaturas em Ciências Biológicas? E mais especificamente: A UNESP possui um projeto unitário de formação de professores de Ciências Biológicas? Para responder as referentes questões adotou-se como referencial teórico Diniz-Pereira (2010).

\section{METODOLOGIA}

A pesquisa documental tem como corpus de análise os Projetos Pedagógicos das Licenciaturas em Ciências Biológicas da UNESP. Inicialmente mapeamos os campus da UNESP que ofertam o curso em questão e caracterizamos cada um deles de acordo com os seguintes aspectos: 1. Modalidade; 2. Turno; 3. Duração; 4. Organização Curricular (Pedagógico); 5. Carga horária (Total/Pedagógico); por fim, foram descritos e analisados os dados obtidos através da pesquisa bibliográfica, documental e mapeamento.

Assim, buscaremos analisar dados que nos permitam debater as principais diferenças estruturantes entre os currículos da Licenciatura ofertada por uma única universidade, com variação de campus, e suas características principais na formação docente.

\section{RESULTADOS}

Ao mapearmos os campus da UNESP, observamos que a universidade conta com 23 unidades, sendo que oito oferecem o curso de Licenciatura em Ciências Biológicas, a saber: Assis, Bauru, Botucatu, llha Solteira, Jaboticabal, Rio Claro, São Vicente e São José do Rio Preto (Quadro 1). É importante destacar que, entre os campus, Assis está em período de reformulação de Projeto Pedagógico de Curso, e não disponibiliza quaisquer dados sobre o curso, não sendo possível sua análise; já Rio Claro, que também passa por reestruturação, disponibiliza dados básicos, porém com vias de análise reduzida e Jaboticabal não possui projeto pedagógico disponível atualmente, há apenas uma organização estrutural do curso, que traz informações limitadas para análise. 
Quadro 1. Principais variações entre os cursos de Licenciatura em Ciências Biológicas da UNESP

\begin{tabular}{|c|c|c|c|c|c|}
\hline Campus & $\begin{array}{l}\text { Modalidade/ } \\
\text { Turno }\end{array}$ & $\begin{array}{l}\text { Duração } \\
\text { (anos) }\end{array}$ & $\begin{array}{l}\text { Organização } \\
\text { Curricular } \\
\text { (Pedagógico) }\end{array}$ & $\begin{array}{l}\text { Carga } \\
\text { horária } \\
\text { (Total) }\end{array}$ & $\begin{array}{l}\text { Carga horária } \\
\text { (Pedagógica) }\end{array}$ \\
\hline BAURU & $\begin{array}{l}\text { Licenciatura/ } \\
\text { Bacharelado - } \\
\text { Integral } \\
\text { Licenciatura - } \\
\text { Noturno }\end{array}$ & $\begin{array}{l}\text { Integral } 4 \\
\text { anos } \\
\text { Noturno } 5 \\
\text { anos }\end{array}$ & $\begin{array}{l}\text { A partir do } 20 \\
\text { ano/2을 } \\
\text { semestre }\end{array}$ & $\begin{array}{l}3.600 \\
\text { horas }\end{array}$ & 1020 horas \\
\hline BOTUCATU & $\begin{array}{l}\text { Licenciatura/Bach } \\
\text { arelado - Integral } \\
\text { Licenciatura - } \\
\text { Noturno }\end{array}$ & $\begin{array}{l}\text { Integral } 4 \\
\text { anos } \\
\text { Noturno } 5 \\
\text { anos }\end{array}$ & $\begin{array}{l}\text { A partir do } 10 \\
\text { ano/2으을 } \\
\text { semestre }\end{array}$ & $\begin{array}{l}4010 \\
\text { horas }\end{array}$ & 1820 horas \\
\hline ILHA SOLTEIRA & $\begin{array}{l}\text { Licenciatura- } \\
\text { Noturno }\end{array}$ & 5 anos & $\begin{array}{l}\text { A partir do 1을 } \\
\text { ano/1을 } \\
\text { semestre }\end{array}$ & $\begin{array}{l}4050 \\
\text { horas }\end{array}$ & 1260 horas \\
\hline JABOTICABAL & $\begin{array}{l}\text { Licenciatura/Bach } \\
\text { arelado- Noturno }\end{array}$ & 4 anos & $\begin{array}{l}\text { A partir do } 20 \\
\text { ano/2ㅇ } \\
\text { semestre }\end{array}$ & 3.540 & 1200 horas \\
\hline $\begin{array}{l}\text { RIO } \\
\text { CLARO }\end{array}$ & $\begin{array}{l}\text { Licenciatura/Bach } \\
\text { arelado - } \\
\text { Integral/ Noturno }\end{array}$ & $\begin{array}{l}\text { Integral } 4 \\
\text { anos } \\
\text { Noturno } 5 \\
\text { anos }\end{array}$ & $\begin{array}{l}\text { A partir do } 10 \\
\text { ano/1을 } \\
\text { semestre }\end{array}$ & $\begin{array}{l}3930 \\
\text { horas }\end{array}$ & 870 horas \\
\hline $\begin{array}{l}\text { SÃO } \\
\text { VICENTE }\end{array}$ & $\begin{array}{l}\text { Licenciatura- } \\
\text { Noturno }\end{array}$ & 5 anos & $\begin{array}{l}\text { A partir do } 10 \\
\text { ano/2을 } \\
\text { semestre }\end{array}$ & $\begin{array}{l}3.600 \\
\text { horas }\end{array}$ & 1080 horas \\
\hline S. J. do RIO PRETO & $\begin{array}{l}\text { Licenciatura/Bach } \\
\text { arelado - Integral }\end{array}$ & 4 anos & $\begin{array}{l}\text { A partir do } 20 \\
\text { ano/1을 } \\
\text { semestre }\end{array}$ & $\begin{array}{l}3915 \\
\text { horas }\end{array}$ & 1575 horas \\
\hline
\end{tabular}

Fonte: pesquisa realizada, 2017.

\section{DISCUSSÃO DOS RESULTADOS}

Em dezembro de 2014, foi apresentada a proposta de reestruturação curricular do Curso de Ciências Biológicas, modalidade Licenciatura no campus de Bauru, para atender a Deliberação do CEE no 111/2012, alterada pela Deliberação CEE no 126/2014 e pela Deliberação CEE no $132 / 2015$, que entrou em vigor para todos os ingressantes do ano 2015 tanto para o período integral, modalidade Licenciatura/Bacharelado como para o período noturno, modalidade Licenciatura. Nessa nova estrutura curricular, os alunos matriculados em período integral fazem a opção de modalidade pela Licenciatura ou Bacharelado ao final do 10 ano do curso. A atual estrutura curricular, correspondente aos currículos do Curso de Licenciatura, integral e noturno, foi mantida até o ano de 2014 (Licenciatura - integral) e 2015 (Licenciatura noturno), porém é importante destacar que é este o projeto pedagógico disponível pelo campus. $O$ atual projeto pedagógico da licenciatura foi implementado no ano de 2004. A carga horária total do curso de Licenciatura obedece aos requisitos da Resolução $\mathrm{CNE} / \mathrm{CP}^{\circ} 2$ de 19 de fevereiro de 2002, segundo os quais indica: I - 1800 (mil e oitocentas) horas de aulas para os conteúdos curriculares de natureza científico-cultural: os componentes curriculares relacionados aos núcleos de conhecimentos do curso garantirão o domínio essencial do conhecimento a área de Ciências Biológicas, tendo carga horária de 3.600 horas no campus de Bauru, sendo 2.580 horas em disciplinas nucleares essenciais e 810 horas em atividades específicas da modalidade Licenciatura; II - 400 (quatrocentas) horas de estágio curricular supervisionado a partir do início da segunda metade do curso: o estágio curricular supervisionado, como um momento de capacitação em serviço; no campus sua integralização refere-se a 405 horas; III - 400 (quatrocentas) horas de prática como componente curricular, vivenciadas ao longo do curso. No campus é necessária a realização de 405 horas. De acordo com Diniz Pereira (2011), o 
termo surgiu, de maneira explícita, na Resolução $\mathrm{CNE} / \mathrm{CP} \mathrm{n}^{\circ}$ 2/2002, que instituiu a duração e a carga horária dos cursos de licenciatura, de graduação plena, de formação de professores da Educação Básica, em nível superior, segundo o qual, a principal intenção com a adoção dessa expressão foi esclarecer a diferença, na lei, entre "prática de ensino" e "estágio curricular supervisionado", além de reforçar o princípio da articulação teoria e prática na formação de professores; IV - 200 (duzentas) horas para outras formas de atividades complementares: a realização de atividades relacionadas será viabilizada por meio da efetiva participação do aluno em um conjunto de atividades de ensino, pesquisa e extensão. $O$ campus exige $o$ cumprimento de 210 horas de Atividades Acadêmicas Científico-Culturais. Desta forma, são destinadas as atividades específicas da Licenciatura, 1020 horas. Cabe destacar que o curso de Licenciatura noturno é idêntico, se comparado às disciplinas presentes na grade curricular e carga horária do curso de Licenciatura oferecido no período integral, e que as disciplinas de caráter pedagógico são iniciadas a partir do quarto semestre do curso. A matriz curricular do curso obedece aos requisitos da Resolução CNE/CP n. 2/2015, que determina o aumento na carga horária desses cursos, como já mencionado.

Desde março de 2014, a Comissão de Reestruturação (Portaria D.IBB no 37/2014, de 17 de abril de 2014) está em processo de estudo e elaboração da reestruturação dos cursos de Licenciatura e de Bacharelado em Ciências Biológicas do Instituto de Biociências do campus de Botucatu planejando, desta forma, a implantação da nova estrutura curricular para 2016. A exigência de $30 \%$ da carga-horária total a ser dedicada às disciplinas didático-pedagógicas exigidas na Deliberação CEE 111/2012, é um item revisto, já que anteriormente a carga horária em disciplinas didático-pedagógicas estava muito aquém do que está sendo exigido pelo Conselho Estadual de Educação (apenas 10,7\%). A Deliberação CEE no 126 de 14 de junho de 2014 em seu Art.10 atribui a formação didáticopedagógica um corpo de conhecimentos educacionais, pedagógicos e didáticos com o objetivo de garantir aos futuros professores dos anos finais do ensino fundamental e ensino médio as competências especificamente voltadas para a prática da docência e da gestão do ensino. Atualmente, a carga horária total do curso de
Licenciatura é de 4010 horas, sendo 810 horas destinadas a disciplinas pedagógicas, 405 horas de Prática como componente curricular, 405 horas de Estágio Supervisionado e 200 horas de Atividades Acadêmicas Científico-Culturais, iniciadas a partir do segundo semestre do primeiro ano de curso. Desta forma, é destinado a atividades específicas da Licenciatura, 1820 horas, atendendo assim a Resolução CNE n. 02, de $1^{\circ}$ de julho 2015 , que atribuiu e determinou as disciplinas de formação docente, o formato da prática como componente curricular e do estágio, necessários e obrigatórios para o aluno obter o diploma de licenciatura. Além disso, o conjunto das disciplinas didático-pedagógicas atende aos incisos I, II, III, IV, V, VI, VII, VIII e IX do artigo 10응 da Deliberação CEE no 111/2012 (alterada pela Deliberação CEE no 126 e 132), assim como as disciplinas de LIBRAS (Decreto no 5626 de 22-122005), Educação Ambiental (Resolução CNE no 2 de 15-6-2012), Educação das Relações ÉtnicoRaciais e o Ensino de História e Cultura AfroBrasileira e Africana (Resolução CNE no 1 de 17-62004) bem como os conhecimentos sobre as especificidades dos alunos com deficiência indicadas na Resolução CNE/CP no 1/2002, que estabelece as Diretrizes Curriculares Nacionais para a Formação de Professores da Educação Básica. Porém, como o PPC do campus foi elaborado no ano de 2014, não atende ao Art. 8․ da Deliberação CEE n. 154/2017.

No campus de Ilha Solteira, as disciplinas propostas na Área de Educação ou denominadas de Pedagógicas foram criadas para atender as normas legais, especialmente a Resolução CNE/CP 2/2002 que institui a duração e carga horária dos cursos de licenciatura, como já mencionado. Para o conjunto das Práticas Pedagógicas como Componentes Curriculares (PPCC) vivenciadas ao longo do curso (desde o primeiro semestre do primeiro ano), seguem disciplinas, que totalizam 420 horas em carga horária. Além das Práticas Pedagógicas como Componente Curricular (PPCC), foram introduzidas mais 210 horas de carga horária na área de educação, atendendo desta forma a Resolução CNE n. 02 , de $1^{\circ}$ de julho 2015 , sendo destinado às atividades específicas da Licenciatura, 1260 horas das 4050 horas totais para integralização curricular.

O curso de Licenciatura em Ciências Biológicas do campus de Jaboticabal não disponibiliza o projeto pedagógico, apenas uma organização estrutural do curso, que traz 
informações limitadas para análise. Desta forma, apresenta apenas dados simplificados relacionados à carga horária do curso, com ausência de datas de criação e implementação, não sendo possível examiná-lo de acordo com Resoluções e Deliberações que normatizam a formação inicial. A carga horária total do curso de Licenciatura é de 3540, sendo 180 horas destinadas às disciplinas pedagógicas, 495 horas de Estágio Supervisionado, 405 horas de Prática como Componente Curricular e 120 de Atividades Acadêmicas Científico-Culturais. Desta forma, é destinado a atividades específicas da Licenciatura, 1200 horas, iniciadas a partir do segundo semestre do segundo ano de curso. Neste campus, podemos destacar as limitadas horas destinadas às disciplinas pedagógicas (teóricas), porém com uma carga horária além do exigido por lei no que se refere ao Estágio Supervisionado, já que a Resolução $\mathrm{CNE} / \mathrm{CP} \mathrm{n}^{\circ} 2$ de 19 de fevereiro de 2002 exige 400 (quatrocentas) horas estágio supervisionado, podendo ser considerado o total de horas destinado às atividades específicas da Licenciatura, em nível aceitável.

O Projeto Pedagógico do Curso de Licenciatura em Ciências Biológicas do campus de Rio Claro encontra-se em período de reestruturação, inviabilizando sua análise. Desta forma, na página eletrônica da Universidade/Campus, foram encontrados dados simplificados no que se refere à carga horária do curso, com informações a partir do ano de 2006, não sabendo assim se ainda seria este o formato do curso atualmente. A carga horária total do curso de Licenciatura é de 3930, sendo 570 horas destinadas a disciplinas pedagógicas, incluindo as horas de Prática como Componente Curricular. Desta forma, é destinado a atividades específicas da Licenciatura, 870 horas, iniciadas a partir do desde o primeiro semestre do primeiro ano. 0 campus não traz informações elementares sobre o Estágio Supervisionado, Atividades Acadêmicas Científico-Culturais, assim como não diferencia as horas destinadas a disciplinas pedagógicas, e as horas de Prática como Componente Curricular.

O processo de Reestruturação Curricular do curso no campus de São Vicente foi feito em 2015 para que houvesse 0 atendimento à Deliberação CEE no111/2012, que define as Diretrizes Curriculares Complementares para a Formação de Docentes para a Educação Básica nos Cursos de Graduação de Pedagogia, Normal Superior e Licenciaturas, oferecidos pelos estabelecimentos de ensino superior vinculados ao sistema estadual. A carga horária total do curso de Licenciatura é de 3.600 horas, sendo 450 horas destinadas a Prática como Componente Curricular, 420 horas ao Estágio Supervisionado e 210 horas de Atividades Acadêmicas CientíficoCulturais. Desta forma, é destinado para as atividades específicas da Licenciatura, 1080 horas, iniciadas a partir do segundo semestre do primeiro ano. Porém, em comparação a outros campus, como o de Botucatu, que destina 810 horas exclusivamente a disciplinas pedagógicas, atendendo aos incisos I, II, III, IV, V, VI, VII, VIII e IX do artigo 10ㅇ da Deliberação CEE no 111/2012 (alterada pela Deliberação CEE no 126 e 132), incluindo em sua carga horária disciplinas de LIBRAS, Educação Ambiental, Educação das Relações Étnico-Raciais e o Ensino de História e Cultura Afro-Brasileira e Africana, bem como os conhecimentos sobre as especificidades dos alunos com necessidades educacionais especiais indicadas na Resolução que estabelece as Diretrizes Curriculares Nacionais para a Formação de Professores da Educação Básica, o campus de São Vicente, se adequa a tal exigência.

O currículo vigente do Curso de Ciências Biológicas no campus de São José do Rio Preto foi implantado através da reestruturação curricular proposta pelo Conselho de Curso de Graduação em Ciências Biológicas (CCGCB) e implantado em 2014 pela Resolução Unesp no 34 de 31 de março de 2015, que em seu Art. 1으, estabelece o Currículo pleno do Curso de Ciências Biológicas modalidades Bacharelado e Licenciatura, do Instituto de Biociências, Letras e Ciências Exatas, do Campus de São José do Rio Preto, sendo integrado por Disciplinas Obrigatórias do Tronco Comum ao Bacharelado e à Licenciatura de Formação Geral do Biólogo, Disciplinas Obrigatórias Específicas do Bacharelado e Disciplinas Obrigatórias Específicas da Licenciatura. Além de cumprir o currículo mínimo obrigatório, é facultada ao aluno da modalidade Licenciatura a possibilidade de complementar sua formação, durante a realização do curso, acrescentando créditos ao seu histórico escolar na forma de disciplinas optativas do Bacharelado. A carga horária total do curso de Licenciatura é de 3915 horas, sendo 960 horas destinadas à formação didático-pedagógica, incluindo as horas de Prática como Componente Curricular, 405 horas ao Estágio Supervisionado e $\mathbf{2 1 0}$ horas de Atividades Acadêmicas Científico-Culturais. Desta forma, é destinado às atividades específicas da 
Licenciatura 1575 horas, iniciadas a partir do primeiro semestre do segundo ano.

\section{CONCLUSÃO}

As disciplinas de formação pedagógica têm o caráter de estabelecer ao estudante de Licenciatura a relação entre o conhecimento de Ciências da Educação e o conhecimento específico da formação do futuro professor, proporcionando assim, o exercício da reflexão sobre a prática, seguindo as definições propostas nas Diretrizes Curriculares Nacionais para a Formação inicial em nível superior (cursos de licenciatura, cursos de formação pedagógica para graduados e cursos de segunda licenciatura) e para a formação continuada. Desta forma, além dos estágios e da carga horária destinada a Prática como Componente Curricular, a Deliberação CEE no 111/2012 (alterada pela Deliberação CEE no 126/2014 e 132/2015, inclui na carga horária dos cursos de Licenciatura, a destinação de no mínimo, 960 horas à formação didático- pedagógica.

Ao analisarmos o Projeto Pedagógico dos Cursos de Licenciatura em Ciências Biológicas ofertados pela UNESP de acordo com a organização curricular (Pedagógico), e a carga horária (Total/Pedagógico), observamos uma larga discrepância em comparação de campus. A menor carga horária total do curso observado foi na Licenciatura do campus de Jaboticabal, sendo 3540 horas exigidas para integralização curricular, em quatro anos no período noturno; versus 4050 horas total, no curso do campus de Ilha Solteira, oferecida em cinco anos no período noturno. Em relação à carga horária destinada especificamente às atividades/conteúdos da Licenciatura, Botucatu é o campus que dedica mais horas a tal formação, sendo 1820 horas (tanto no período integral - quatro anos; como no período noturno - cinco anos); versus ao campus de Rio Claro, que atribui apenas 870 horas (tanto no período integral - quatro anos; como no período noturno - cinco anos).

Em relação à organização curricular, onde se encontram as atividades/conteúdos da Licenciatura, Ilha solteira e Rio Claro são os campus que dedicam horas a formação pedagógica desde o primeiro semestre do curso, a partir do 1 o ano/1을 semestre; porém, existem outros campus da mesma instituição de ensino que adiam o início das atividades/conteúdos destinados a formação de professores, como Bauru (Integral - 4 anos e Noturno - 5 anos) e
Jaboticabal (Noturno - 4 anos), que as ofertam a partir do 20 ano/2ㅇ semestre.

Desta forma pode-se destacar que os currículos dos cursos de Licenciatura passam cada vez mais por alterações devido ao cumprimento Resoluções e Deliberações que se alteram a todo o momento. Assim, as disciplinas responsáveis pela formação à docência passam a não cumprir seu propósito real - a formação docente.

Portanto, em acordo com André et al. (2012), ao problematizarmos a relevância da presença no currículo de disciplinas com conteúdos pedagógicos nos cursos de licenciatura, defendemos a importância de um currículo estruturado para a vivência universitária de futuros professores, já que o curso em questão tem um papel fundamental na socialização profissional e na construção da identidade dos professores, ou seja, no desenvolvimento de saberes, habilidades, atitudes, valores que constituem a especificidade do ser professor, atribuindo ao currículo da licenciatura, o encargo da identidade docente.

\section{REFERÊNCIAS}

ANDRÉ, M. E. D. A. et al. O papel do professor formador e das práticas de licenciatura sob o olhar avaliativo dos futuros professores. Revista Portuguesa de Investigação Educacional, PortoPT, v. 12, p. 101-123, 2012. https://doi.org/10.1590/S0101$\underline{73302010000400016}$

BRASIL. Parecer CNE n. 28, de 2 de outubro de 2001. Dá nova redação ao Parecer $\mathrm{CNE} / \mathrm{CP} \mathrm{n}^{\circ}$ 21/2001, que estabelece a duração e carga horária dos cursos de formação de professores da educação básica, em nível superior, curso de licenciatura, de graduação plena. Disponível em: $<$ http://portal.mec.gov.br/cne/arquivos/pdf/028. pdf $>$. Acesso em: 13 abr. 2017.

BRASIL. Resolução CNE no 01, de 18 de fevereiro de 2002. Institui as Diretrizes Curriculares Nacionais para a Formação de Professores de Educação Básica, em nível superior, curso de licenciatura, de graduação plena. Disponível em: <http://www.prograd.ufu.br/legislacoes/resoluca o-cnecp-no-1-de-18-de-fevereiro-de-2002-

diretrizes-curriculares-nacionais-para>. Acesso em: 13 abr. 2017.

BRASIL. Resolução CNE $\mathbf{n . 0 2}$, de 19 de fevereiro de 2002. Institui a duração e a carga horaria dos 
cursos de licenciatura, de graduação plena, de formação de professores da Educação Básica em nível superior. Disponível em: <http://portal.mec.gov.br/cne/arquivos/pdf/CPO 22002.pdf>. Acesso em: 13 abr. 2017.

BRASIL. Resolução CNE no $\mathbf{0 2}$, de $1^{\circ}$ de julho de 2015. Define as Diretrizes Curriculares Nacionais para a formação inicial em nível superior (cursos de licenciatura, cursos de formação pedagógica para graduados e cursos de segunda licenciatura) e para a formação continuada. Disponível em: <http://www.prograd.ufu.br/legislacoes/resoluca o-cnecp-no-02-de-01-de-julho-de-2015diretrizes-curriculares-nacionais-para>. Acesso em: 13 abr. 2017.

DIAS-DA-SILVA, M. H. G. F. Política de formação de professores no Brasil: as ciladas da reestruturação das licenciaturas. Perspectiva, Florianópolis, v. 23 , n. 2 , p. 381-406, jul./dez. 2005.

GATTI, B. A.; NUNES, M. M. R. Formação de professores para o ensino fundamental: estudo de currículos das licenciaturas em pedagogia, língua portuguesa, matemática e ciências biológicas. 1. ed. São Paulo: Fundação Carlos Chagas, 2009.

GATTI, B. A. Formação de professores no Brasil: características e problemas. Educação \& Sociedade, Campinas, v. 31, n. 113, p. 1355-1379, out./dez. 2010.

GARCIA, M. M. A. Textos e Contextos na Reforma das Licenciaturas: o caso da UFPel. Educação \& Realidade, Porto Alegre, v. 35 , n. 2, p. 229-252, mai./ago. 2010.

MIZUKAMI, M. da G. M. Docência, trajetórias pessoais e desenvolvimento profissional. In: REALI, A. M.; MIZUKAMI, M. da G. M. (orgs.). Formação de professores: tendências atuais. São Carlos: Edufscar, 1996. p. 59-91.

MOREIRA, P. C. $3+1$ e suas (In)Variantes (Reflexões sobre as possibilidades de uma nova estrutura curricular na Licenciatura em Matemática). Bolema, Rio Claro, v. 26, n. 44, p. 1137-1150, dez. 2012. https://doi.org/10.1590/S0103636X2012000400003
SÃO PAULO (Estado). Conselho Estadual de Educação. Deliberação CEE no 111/2012. Fixa Diretrizes Curriculares Complementares para a Formação de Docentes para a Educação Básica nos Cursos de Graduação de Pedagogia, Normal Superior e Licenciaturas, oferecidos pelos estabelecimentos de ensino superior vinculados ao sistema estadual. Diário Oficial do Estado de São Paulo, SP, 15 mar. 2012.

SÃO PAULO (Estado). Conselho Estadual de Educação. Deliberação CEE no 126/2014. Altera dispositivos da Deliberação 111/2012. Diário Oficial do Estado de São Paulo, SP, 14 jun. 2014.

Recebido para publicação em: 19/10/2017

Revisado em: 14/11/2017

Aceito em: 18/01/2018 